\title{
PRODUÇÃO E COLABORAÇÃO CIENTÍFICA DOS DOCENTES DAS PÓS-GRADUAÇÕES EM BIBLIOTECONOMIA E CIÊNCIA DA INFORMAÇÃO DA REGIÃO NORDESTE: ANÁLISE NO PERÍODO DE 2013 A 2017
}

\author{
PRODUCTION AND SCIENTIFIC COLLABORATION OF \\ POST-GRADUATE TEACHER IN BIBLIOTECONOMY \\ AND INFORMATION SCIENCE IN THE NORTHEAST \\ REGION: ANALYSIS FROM 2013 TO 2017
}

Ana Karolyne Nogueira de Sousa ${ }^{a}$

Paulo Eduardo Silva Lins Cajazeirab

\begin{abstract}
RESUMO
Introdução: Por considerar a ciência em uma perspectiva acumulativa das produções e social nas relações de coautorias. Objetivo: analisar os indicadores de produção e colaboração científica dos docentes dos sete programas de pós-graduação stricto sensu da região Nordeste em Biblioteconomia e Ciência da Informação, do período de 2013 a 2017. Metodologia: tendo como métodos a bibliometria e análise de redes sociais de coautoria. Resultados: Em relação aos periódicos científicos, foi demonstrado que os docentes têm optado pelas revistas de menor periodicidade, as trimestrais, assim como, por práticas endógenas, com uso massivo dos periódicos pertencentes aos próprios programas. Conclusões: busca colaborar com o entendimento, reconhecendo as características e a evolução da área, identificando as especificidades e os padrões, com o propósito de promover discussões, contribuições e reflexões sobre as produções da área.
\end{abstract}

Descritores: Produção científica. Bibliometria. Análise de redes de coautorias.

\footnotetext{
a Mestra em Biblioteconomia, pela Universidade Federal do Cariri (UFCA). Bibliotecária/ Documentalista do Instituto Federal de Educação, Ciência e Tecnologia do Ceará. E-mail: anikarolyne@hotmail.com

b Doutor em Comunicação e Semiótica, pela Pontifícia Universidade Católica de São Paulo (PUC/SP). Professor da Universidade Federal do Cariri no Curso de Jornalismo e no Programa de Pós-Graduação em Biblioteconomia. E-mail: paulo.cajazeira@ufca.edu.br
} 


\section{INTRODUÇÃO}

Até o século XIX, o propósito da universidade era ensinar e transmitir conhecimento com o objetivo de desenvolver habilidades técnico-científicas nos alunos. Na passagem do século XIX para o século XX, com a primeira Revolução Acadêmica, introduziu-se as atividades de pesquisa aos sistemas tradicionais de ensino, passando o docente a gerar conhecimento por via de experimentos e descobertas, e somente na segunda metade do século XX se inicia a segunda Revolução Acadêmica, representada pela interação entre instituições acadêmicas e empresariais, em resposta à necessidade da indústria em produzir Pesquisa e Desenvolvimento (P\&D).

Nesse momento, a universidade assumiu, além de suas clássicas atividades de ensino e pesquisa, a função de agente de desenvolvimento econômico, local e regional (MELO, 2015). Isto posto, o histórico da universidade tem um caminhar de representações que incidem na pesquisa como força motriz e grande aliada ao progresso da ciência e da sociedade.

Como a ciência tem como um dos objetivos a produção do conhecimento científico, constituído de todo um sistema de comunicação científica, as universidades, principalmente os programas de pós-graduação, são predominantemente reconhecidas como as maiores produtoras de conteúdo e de atividades científicas. Os docentes, por estarem intrinsecamente relacionados aos processos de disseminação da informação e construção do conhecimento em todos os ramos da ciência, têm um papel importante na produtividade da ciência e no desenvolvimento social, tecnológico e econômico da sociedade.

Diante disso, houve a necessidade de mensurar pela quantidade, a qualidade e o impacto das publicações e produções relativas à ciência, proporcionando o advento da bibliometria. Ou seja, trata-se de um estudo métrico, desenvolvido para gerar indicadores que proporcionem a análise da produção científica, possibilitando o reconhecimento dos desempenhos dos cientistas, bem como a caracterização e a evolução das áreas do conhecimento. Estudos sociométricos complementam as análises bibliométricas através da Análise de Redes Sociais (ARS), que configuram como o estudo das relações 
de colaboração entre os pesquisadores, por identificar as redes e ligações entre os grupos que produzem por meio do mapeamento das coautorias e das citações.

Ressalta-se que no Brasil o desafio de construir indicadores de produção científica é maior, dada à precariedade das fontes de informação disponíveis e, em alguns casos, sua ausência. Entretanto, os indicadores vêm ganhando importância com os instrumentos para análise da atividade científica e das suas relações e impactos com o desenvolvimento econômico e social (KOBASHI, SANTOS, 2006).

A construção desses indicadores tem sido incentivada pelos órgãos de fomento à pesquisa como meio para se obter uma visão acurada da produção de ciência, a fim de ampliar as análises e as dimensões das variáveis relacionadas ao fluxo da informação científica, subsidiar políticas científicas e avaliar os resultados. Os indicadores de produtividade são usados como referência pelas agências de fomento e financiamento do país, para acompanhar o progresso e avaliar a produtividade dos pesquisadores dos programas de pósgraduação, utilizando os métodos bibliométricos.

Galindo e Azevedo Netto (2008) declaram que o Brasil ainda permanece tendo a meta de realizar uma infraestrutura nacional de pós-graduação bem distribuída, sustentável e equilibrada, tendo em conta que o desenvolvimento do sistema de pós-graduações no Brasil, em algumas regiões, principalmente no Norte e o Nordeste, não conseguiram se articular localmente e formar aparatos de pesquisa que dessem sustentabilidade a programas de pós-graduação. De acordo com Sidone, Haddad e Mena-Chalco (2016), o Brasil tem enorme heterogeneidade espacial das atividades de pesquisa científica, em que o padrão regional da distribuição das publicações e dos pesquisadores é altamente concentrado na região Sudeste, com destaque às capitais dos estados.

Mencionam que apesar da heterogeneidade, são crescentes as pesquisas que buscam a compreensão determinante das redes de colaboração científica, que podem desempenhar papel primordial relacionado aos desafios das políticas de Ciência, Tecnologia e Inovação (CT\&I), principalmente por consistir em um 
instrumento essencial para visualizar as dinâmicas dos grupos de pesquisadores, consequentemente, facilitar os fluxos da informação e do conhecimento para aumentar a concentração de publicações na região Nordeste, uma vez que, segundo Silva et al (2006, p. 80), "[...] a ciência funciona bem quando a comunidade de pesquisadores é densamente conectada".

Diante das problemáticas quanto às fontes de informação, do cenário heterogêneo científico brasileiro com as pós-graduações e por não haver indicadores bibliométricos ou mapeamentos das redes de coautoria das produções dos sete programas de pós-graduação de Biblioteconomia e Ciência da Informação, com o escopo da região Nordeste, se faz necessário fornecer informações para a compreensão da dinâmica externa das produções internas das redes de coautoria dos docentes regionais da área, a fim de complementar as avaliações formais feitas pela Coordenação de Aperfeiçoamento de Pessoal de Nível Superior (Capes) e identificar as características que formam as comunidades dos docentes. Por isso, surge o seguinte problema de pesquisa: Como se configuram os indicadores bibliométricos de produção científica e das redes de coautoria dos docentes das pós-graduações de Biblioteconomia e Ciência da Informação $(\mathrm{Cl})$ na região Nordeste?

\section{REVISÃO TEÓRICA: CONTEXTOS HISTÓRICO E CONCEITUAL}

Mueller (1988) menciona que a produção científica dos docentes dos cursos de pós-graduação, juntamente com as dissertações e teses de seus alunos, se constitui na maior fonte de estudos na área de Biblioteconomia e Ciência da Informação no País. Nesta perspectiva, esta pesquisa repousa no entendimento de que o sistema de produção e comunicação científica é um instrumento poderoso de transformação e colaboração, que possibilita o despertar de saberes de um mundo cheio de indagações e de experiências nos contextos sociais, tecnológicos e científicos.

Com intuito de responder o questionamento da pesquisa, foi definido o objetivo geral, que buscou analisar a produção e a colaboração científica dos docentes dos programas de pós-graduação stricto sensu do Nordeste em Biblioteconomia e Ciência da Informação, no período de 2013 a 2017, por meio 
de indicadores bibliométricos e da análise de redes de coautoria.

Ressalta-se, intentando que a Biblioteconomia e $\mathrm{Cl}$ são campos que oferecem potencial diálogo de interdisciplinaridade com várias áreas do conhecimento, tendo como base os objetivos e linhas de pesquisas dos programas da região, acredita-se haver participação de colaboradores e docentes de várias áreas, principalmente as áreas mais próximas e correlatas nas produções analisadas, refletindo diferentes práticas de interdisciplinaridades na área.

Com isso, nesta pesquisa buscar-se-á identificar: se existem poucos docentes muito produtivos e muitos autores com poucas publicações; se há relações entre os docentes em diversas linhas e programas da região Nordeste e se participam de uma rede densa; se a quantidade de colaborações proporciona maiores índices de produtividade dos docentes; e, se existe uma demanda de fortalecimento das redes de colaboração entre os docentes na região Nordeste.

\subsection{As TECNOLOGIAS dE INFORMAÇÃo E DE COMUNICAÇÃo (TICS)}

São dois campos do conhecimento que tiveram sua trajetória e advento marcados pelas transformações da sociedade, que foram predominantes para o seu desenvolvimento, precipuamente com na produção e disseminação da informação, sendo tratadas e respaldadas cada vez mais a sua importância no meio econômico, social, cultural e político. Diante disso, impulsionaram discussões teóricas e práticas, a fim de poder suprir as necessidades informacionais, haja vista que em maior ou menor grau elas tratam da influência das Tecnologias de Informação e de Comunicação na sociedade e na cultura contemporânea, sobretudo da informação, a qual se encontra em forma de fluxos na rede, possibilitando o gerenciamento, organização, representação, recuperação e disseminação.

Com isso, foi feito um estudo histórico e conceitual sobre esses campos para que permitisse maior compreensão, caracterização e aprofundamento sobre seus domínios, configurações, abordagens e particularidades que as formam, corroborando para as discussões e análises nos resultados desta 
pesquisa.

Para que se possa entender melhor a Biblioteconomia, é necessário conhecer a sua longa tradição e desenvolvimento como campo de conhecimento, como também as definições. Dessa maneira, Silva (2010) concebe seu conceito relacionando aos contextos epistemológicos e etimológicos, dividindo em três palavras: biblio - teca - nomia, sendo o primeiro associado a livros, o segundo relativo à caixa, com sentido de algo que arranja, arruma ou organiza, e o terceiro referente à norma estabelecida para um determinado fim.

Diante disso, o autor pondera que a Biblioteconomia pode ser considerada, em sua essência, como uma norma estabelecida, isto é, um

[...] conjunto de normas para a organização de acervos de uma biblioteca que está embasada pelos códigos e materiais de catalogação, classificação, indexação e de outros instrumentos técnicos de organização, visando promover disseminação e acesso à informação à sociedade (SILVA, 2010, p. 63).

Assim sendo, significa afirmar que tem o intuito de organização e estruturação para qualquer suporte em um espaço que designe o tratamento e o registro do conhecimento, a fim de que permita a recuperação e o acesso das informações. Desse modo, é possível ir muito além de apenas um somente suporte ou de um lugar específico, mas tendo como foco a biblioteca. Sendo, portanto, uma área que abrange um arcabouço teórico de princípios normativos, técnicos de organização, representação e acesso à informação.

Para Souza (1996, p. 2) a Biblioteconomia é

[...] uma ciência que se determina por uma prática social e que se consolida pelo registro e codificação das experiências positivas no uso, organização e controle dos documentos que são buscados pelos seus conteúdos [informação].

Percebe-se que o autor relaciona a área com a empiria, com as técnicas, fazendo menção à prática social que a constitui, algo que é bastante representativa e reconhecida dentro e fora da área, mas pode ser ampliado dentro de uma perspectiva científica, como também para os ambientes digitais. Dentro desse contexto, outros autores, como Le Coadic (2004) e Ortega (2004), classificam e representam usualmente a Biblioteconomia como uma área voltada para as atividades essencialmente técnicas e práticas de organização de 
acervos em bibliotecas.

É importante ressaltar que Rodrigues e Dumont (2004) assevera que na Biblioteconomia, como em tantas outras áreas do conhecimento, se procura romper com uma concepção de profissional eminentemente técnico para se buscar um perfil mais interdisciplinar, a fim de que possa conseguir adaptar a realidade heterogênea do mundo globalizado, tendo em vista que os usuários são mais exigentes, além do constante aperfeiçoamento dos aparatos tecnológicos.

Essa afirmação busca principalmente esclarecer o contexto de exigências e problemas em que a Sociedade da Informação e do Conhecimento convenciona aos profissionais para o desenvolvimento de uma área do conhecimento, e para a Biblioteconomia alguns desafios precisam ser resolvidos devido ao seu percurso histórico que a caracteriza bastante pelo desenvolvimento de técnicas de organização, tratamento e preservação dos registros, mas que foram ao longo tempo consolidando as práticas científicas. Portanto, para clarificar melhor sobre estes conceitos e entendimentos, deve-se olhar para a história, para então determinar e a classificar o que é a Biblioteconomia atualmente na sociedade.

Nesse aspecto, no que tange à historicização da área, Russo (2010) afirma que a evolução da Biblioteconomia tem se caracterizado por duas orientações principais: passando da erudição para o serviço ao público. No que se refere à longa tradição de sua prática e erudição, pode-se mencionar e relacionar as primeiras evidências de bibliotecas com o início da Biblioteconomia. Entende-se que com o desenvolvimento das civilizações, foram surgindo espaços para a guarda desses registros, com diversas finalidades.

Segundo Ortega (2004, p. 1),

Parte-se das primeiras evidências de organização de documentos segundo seus conteúdos, apontando estes processos e as bibliotecas primitivas da Antiguidade que os realizavam como a origem do que depois foi denominado Biblioteconomia.

Desse modo, está atrelada aos marcos históricos quanto à organização, o armazenamento e a preservação dos registros do conhecimento, da mesma maneira que as grandes bibliotecas que marcaram épocas, como a Biblioteca de 
Alexandria ${ }^{1}$ e de Ebla, que foram se aperfeiçoando nos suportes e nas técnicas. A biblioteca nesta época, até a Idade Média, era caracterizada como espaço de custódia e preservação dos documentos.

Com o surgimento da imprensa móvel e do Renascimento, aumentou consideravelmente os números de livros, coleções e com o passar dos tempos, o acesso à classe mais esquecida da sociedade, de forma que proporcionou um novo papel para as bibliotecas nacionais, e o surgimento posterior, um viés social através das bibliotecas públicas e universais. Nesse contexto, houve a valorização da democracia e a necessidade da disseminação da informação, que impulsionou para novos procedimentos e técnicas de organização, principalmente com o bibliotecário Gabriel Naudé (1600-1653), que se destacou pela sua atuação e conhecimento, em que soube avançar os estudos conceituais da área e trazer novos olhares sociais com a belíssima obra Advis pour dresser um bibliothéque (1627), sendo este o primeiro manual para bibliotecários, que formalizou princípios que norteiam o funcionamento, formação e organização de bibliotecas, além da ideia de ordem bibliográfica.

É importante mencionar que a Revolução Francesa (1789-1799) também contribuiu para este desenvolvimento por meio da consolidação da biblioteca pública, de modo que levou à profissão mais reconhecimento, igualmente elevou a novos patamares na prática e nos métodos em vários aspectos de organização, gestão, disseminação e mais visibilidade com o papel social, tal como novos serviços para a comunidade, que cresciam vertiginosamente.

Dias (2000) menciona que novos problemas também foram surgindo, de tal modo que exigia mais que uma abordagem intuitiva, que resultaram em uma biblioteconomia-ciência, antes mesmo do efetivo marco referencial da fundação da Graduate Library School da University of Chicago em 1928, havia um esforço reflexivo ou teórico na área, remetendo a Melvil Dewey no desenvolvimento do sistema de classificação em 1876, a Classificação Decimal de Dewey (CDD).

Além disso, muitos estudos foram feitos e processos para solucionar os

\footnotetext{
1 "[...] é talvez a melhor representante das Bibliotecas da Era Ancestral. Esse paradigma, tipicamente custodial, atende a uma pequena quantidade de estudantes, pesquisadores e líderes religiosos formando um grupo seleto de utilizadores" (MIRANDA, 2012, p. 103).
} 
problemas de ordenação até o surgimento dos sistemas de classificação, que segundo o autor supracitado, constituem uma abordagem igualmente identificada com o processo de criação científica a uma preocupação sistemática. Araújo (2013) esclarece que os precursores do estabelecimento do projeto de constituição científica da Biblioteconomia advieram da consolidação de teorias, das regras de catalogação e dos sistemas de classificação bibliográfica.

A Biblioteconomia se apresenta na ciência por meio de procedimentos técnicos e práticos, caracterizado por uma época de revolução tecnológica e industrial do século XVIII, que para Silva $(2010$, p. 15) pode ser "[...] compreendida como uma disciplina profissional em constante processo de aprimoramento técnico-normativo". Ressalta-se que o desenvolvimento técnico da área não desmerece nem a desqualifica das demais áreas do conhecimento, mas como uma peculiaridade da área, principalmente devido seu contexto histórico, que iniciou formalmente suas produções intelectuais somente com o primeiro programa de doutoramento em Biblioteconomia. Trata-se da Universidade de Chicago que foi bastante relevante, elevando o nível das pesquisas, abrangendo as discussões e contribuições epistemológicas, bem como reflexões sobre as relações da sociedade com a biblioteca, sobretudo devido às dificuldades em se estabelecer cientificamente. Contudo, Ortega (2004) afirma que muitas inovações de modelos e técnicas, aparatos tecnológicos foram ignorados devido à influência da Universidade de Chicago, o que gerou limitações para os estudos e aplicações na área.

Dentro desse contexto houve o surgimento da Documentação ${ }^{2}$, vindouro do rompimento dos bibliógrafos com os bibliotecários, ocasionado devido ao aumento das pesquisas científicas e dos trabalhos de bibliografias, especialmente ao crescimento dos periódicos, que intensificaram a necessidade de novos procedimentos para o tratamento, recuperação e acesso aos

\footnotetext{
2 Documentação é definida como a "[...] arte de coletar, classificar e tornar facilmente acessíveis os registros de todas as formas de atividade intelectual. É o processo pelo qual o documentalista pode colocar ante o especialista criador a literatura existente sobre o campo de sua investigação, a fim de que ele possa tomar pleno contato com as realizações anteriores em seu terreno, e dessa forma evitar a dispersão de esforço na realização de uma tarefa já executada" (BRADFORD, 1961, p. 68).
} 
documentos não tradicionais. Com isso, houve conflitos de interesses no período final do século $X I X$ até metade do século $X X$ entre os bibliotecários, que focalizavam mais na compreensão e na preocupação com o novo papel, as melhorias, os serviços para a biblioteca pública, impulsionados pela Escola de Chicago, e, os bibliógrafos, representados, principalmente na Europa, que necessitavam trabalhar novas e diferentes técnicas de tratamentos para os documentos. Diante desse quadro de interesses adversos, proporcionou a separação e o aprofundamento especializado nos diversos suportes e, consequentemente o surgimento de uma nova área.

Segundo Siqueira (2010) foi desenvolvida simultaneamente com as atividades referentes à biblioteca pública, as práticas documentais delineadas a partir dos trabalhos de Paul Otlet e La Fontaine, que sistematizaram conceitos para Documentação com base nos estudos bibliográficos. Assim sendo, Paul Otlet e La Fontaine foram os principais contribuintes e precursores da Documentação do controle bibliográfico universal, da fundação do Instituto Internacional de Bibliografia (IIF), bem como de novas técnicas, aplicações, ferramentas para o registro e de um sistema de classificação que correspondesse às necessidades de tratamento para os diferentes tipos de documentos, a Classificação Decimal Universal (CDU). Ademais, houve a obra "Traité de Documentation", de Otlet de 1934, que dispõe de importantes conceitos, como de documentos, até mesmo "[...] de forma visionária, antecipou o surgimento de novas tecnologias, em especial os sistemas de hipertexto e hipermídia, frutos da revolução tecnológica desencadeada depois da II Guerra Mundial" (RUSSO, 2010, p. 41).

Ressalta-se, segundo Vanz (2003), que a bibliometria era conhecida por 'bibliografia estatística', que só foi mencionada pela primeira vez por Otlet em 1934, na aludida obra Traité de Documentation, como parte da bibliografia "[...] que se ocupa da medida ou da quantidade aplicada ao livro" (OTLET, 1986, p. 20). Contudo, o termo apenas se popularizou a partir de 1969 no seminário anual do Documentation Research and Training Centre (DRTC). Contudo, a bibliometria, segundo Araújo (2006), foi iniciada por Hulme em 1922 por aplicar técnicas estatísticas e matemáticas para descrever aspectos da literatura e de 
outros meios de comunicação.

Desde sua origem é marcada pela preocupação na análise da produção científica escrita, a busca de benefícios práticos imediatos para bibliotecas, no que tange o desenvolvimento de coleções, gestão de serviços bibliotecários, ademais na promoção do controle bibliográfico (FIGUEIREDO, 1977). A necessidade de estudos sobre a produção e comunicação científica desencadeou novos formatos de estudos para além dos livros e da produtividade, como na disseminação e uso da informação. Com isso, originaram novas técnicas, denominações, estudos e leis, que são mais bem exploradas no capítulo mais adiante.

\section{METODOLOGIA}

O plano metodológico tem por base os objetivos e a problemática do presente trabalho, e, para cumpri-las e solucioná-la, delineou-se a pesquisa como método dedutivo por estar tratando de uma estrutura lógica construída a partir da produção científica dos docentes dos programas de pós-graduação da região Nordeste, cujos procedimentos foram realizados acerca de indicadores bibliométricos e de análise de redes coautoria, haja vista que tem como bases características de mensuração e quantificação das produções e das redes de colaboração por via da frequência e dos níveis de relacionamento entre os dados para melhor caracterizá-los.

Nesta perspectiva, a pesquisa está pautada na teoria de pensamento Estruturalista, posto que aborda a ciência através do estudo de relações e ligações que estruturam e condicionam a uma perspectiva de realidade sobre o fenômeno contemplado. Triviños (2011) define esta abordagem com a pretensão de descobrir a estrutura dos fenômenos, coisas, objetos e sistemas que existem na realidade, penetrar em sua essência para determinar as suas ligações e relações determinantes.

A natureza é considerada aplicada, quanto aos objetivos da pesquisa, este se caracteriza como estudo de caso, exploratório, descritivo e de levantamento de dados. As pesquisas descritivas são, juntamente com a exploratória, as que permitem realizar um aprofundamento detalhado e completo 
da realidade entre as relações, os padrões dos dados e suas características. A escolha do estudo de caso se deu pela importância quanto à coleta de dados, tendo em vista que a pesquisa identifica os padrões que definem as áreas de produção e produtividade dos docentes, os tipos de coautoria e os níveis de colaboração entre os programas, regiões, estados, países e instituições. Quanto aos procedimentos, têm cunho bibliográfico e documental, tendo em conta que foram utilizados os currículos dos docentes da plataforma Lattes, disponibilizada pelo CNPq.

O estudo tem como abordagem a pesquisa quali-quantitativa, haja vista estar voltado tanto para a compreensão de um determinado processo social, quanto para as relações estabelecidas entre as variáveis (GODOI; BANDEIRADE-MELLO; SILVA, 2006). Nesse caso, foi verificado que a melhor metodologia seria esta, que se mostra apropriada quanto às medidas quantificáveis das variáveis e na interpretação das relações de significado dos fenômenos, a julgar que através dos estudos métricos foram gerados resultados quantitativos de produção e qualitativos referentes a análises e interpretações dos resultados, portanto, foram alinhadas no decorrer das discussões. Creswell (2007) aponta a adequação do método misto para as pesquisas envolvidas na necessidade, tanto de explorar quanto de explicar os fenômenos em estudo.

O objetivo desta pesquisa se delineia em explorar a produção científica dos docentes das sete pós-graduações stricto sensu em Biblioteconomia e Ciência da Informação do Nordeste, durante o período de 2013 a 2017. Dessa forma, foi optado pelo uso dos indicadores bibliométricos devido ao nosso objetivo de mapear as produções, bem como aplicação das leis de Bradford e Lotka, a fim de determinar o núcleo dos periódicos e compreender a produtividade dos docentes. Assim, se busca responder as seguintes questões: Quais docentes são mais produtivos? Quais periódicos e eventos são mais publicados? Quais IES são mais profícuas? Os docentes são colaborativos? A rede dos docentes é densa? A colaboração aumenta ou diminui nos anos de estudo? A colaboração proporciona um aumento da produtividade? Os docentes colaboram mais com pesquisadores externos ao programa de regiões e países diferentes? Os mais colaborativos são os mais prolíferos? Como se configuram 
as redes de coautoria entre as pós-graduações de Biblioteconomia e Ciência da Informação na região Nordeste?

\section{DELIMITAÇÃO DO CAMPO DE PESQUISA}

O corpus da pesquisa é formado pelas produções científicas dos noventa e nove docentes do quadro permanente das instituições dos sete programas de pós-graduação da região Nordeste. Dos programas que foram estudados, quatro são acadêmicos e três profissionais, sendo eles:

Quadro 1 - Programas de pós-graduação na região Nordeste

\begin{tabular}{|l|l|c|c|c|}
\hline \multicolumn{1}{|c|}{ Programa } & \multicolumn{1}{|c|}{ Instituição de Ensino } & \multicolumn{1}{c|}{$\begin{array}{c}\text { Área } \\
\text { básica }\end{array}$} & Docentes & Mod. \\
\hline $\begin{array}{l}\text { Ciência da } \\
\text { Informação }\end{array}$ & $\begin{array}{l}\text { Universidade Federal da } \\
\text { Bahia (UFBA) }\end{array}$ & $\begin{array}{l}\text { Ciência da } \\
\text { Informação }\end{array}$ & 16 & Aca. \\
\hline $\begin{array}{l}\text { Ciência da } \\
\text { Informação }\end{array}$ & $\begin{array}{l}\text { Universidade Federal da } \\
\text { Paraíba (UFPB) }\end{array}$ & $\begin{array}{l}\text { Ciência da } \\
\text { Informação }\end{array}$ & 23 & Aca. \\
\hline $\begin{array}{l}\text { Ciência da } \\
\text { Informação }\end{array}$ & $\begin{array}{l}\text { Universidade Federal de } \\
\text { Pernambuco (UFPE) }\end{array}$ & $\begin{array}{l}\text { Ciência da } \\
\text { Informação }\end{array}$ & 15 & Aca. \\
\hline $\begin{array}{l}\text { Ciência da } \\
\text { Informação }\end{array}$ & $\begin{array}{l}\text { Universidade Federal do } \\
\text { Ceará (UFC) }\end{array}$ & $\begin{array}{l}\text { Ciência da } \\
\text { Informação }\end{array}$ & 12 & Aca. \\
\hline Biblioteconomia & $\begin{array}{l}\text { Universidade Federal do } \\
\text { Cariri (UFCA) }\end{array}$ & $\begin{array}{l}\text { Bibliotecono } \\
\text { mia }\end{array}$ & 17 & Prof. \\
\hline $\begin{array}{l}\text { Gestão da } \\
\text { Informação e do } \\
\text { Conhecimento }\end{array}$ & $\begin{array}{l}\text { Universidade Federal do } \\
\text { Rio Grande do Norte } \\
\text { (UFRN) }\end{array}$ & $\begin{array}{l}\text { Ciência da } \\
\text { Informação }\end{array}$ & 09 & Prof. \\
\hline $\begin{array}{l}\text { Ciência da } \\
\text { Informação }\end{array}$ & $\begin{array}{l}\text { Universidade Federal de } \\
\text { Sergipe (UFS) }\end{array}$ & $\begin{array}{l}\text { Ciência da } \\
\text { Informação }\end{array}$ & 07 & Prof. \\
\hline
\end{tabular}

Fonte: Coordenação de Aperfeiçoamento de Pessoal de Nível Superior (2017).

$\mathrm{Na}$ coleta dos dados, foram pesquisadas nas páginas institucionais da internet dos programas, a relação nominal dos docentes permanentes, como também, foi feito contato com os devidos departamentos para conferência da relação encontrada. Com a lista confirmada, prosseguiu a pesquisa na Plataforma Lattes na busca pelas produções nos currículos dos docentes vinculados às pós-graduações. Para o tratamento e a tabulação dos currículos Lattes foi utilizado o software scriptLattes, que compilou automaticamente os currículos em formato Hyper Text Markup Language (HTML) no dia 12 de setembro de 2018, isto possibilitou a organização dos dados, delimitados pelas 
categorias de análise e quantificação das produções dos anos de 2013 a 2017. Foram gerados sete relatórios, um para cada programa em estudo. Com base nestes relatórios obteve-se amostra da pesquisa com o total de 2.653 produções. Segue na tabela 1 o quantitativo referente a cada produção:

Tabela 1 - Amostra da pesquisa

\begin{tabular}{lc}
\hline \multicolumn{1}{c|}{ Produções } & Total \\
\hline Artigos em periódicos & 882 \\
Livros publicados & 113 \\
Capítulos de livros & 346 \\
Trabalhos completos em anais & 925 \\
Resumos expandidos em anais & 147 \\
Resumos publicados em anais & 209 \\
\hline
\end{tabular}

Fonte: dados da pesquisa.

Com uso do ScripLattes, foram extraídos e organizados os dados bibliográficos dos docentes, bem como informações numéricas sobre as referidas tipologias e eventos publicados, as coautorias e as instituições vinculadas. Foi verificada a padronização dos metadados, principalmente nas correções das grafias dos nomes dos atores e dos periódicos, tendo em vista que esse procedimento é essencial para unificação e a retirada das duplicidades dos dados. É importante também salientar problemas nos relatórios do ScripLattes quanto à localização dos resultados, pois nos relatórios muitas produções não foram contabilizadas dentro dos campos referentes aos anos de recorte, mas em itens sem ano. Deduz-se que esses problemas podem ter relação com erros no preenchimento dos currículos dos docentes. Apesar disso, todas as publicações localizadas nos itens de sem ano foram também contabilizadas e devidamente analisadas. Outra questão pertinente na análise dos currículos foi a presença de duas docentes pertencerem a mais de um programa entre os sete estudados. Diante disso, localizou-se no site Sucupira os relatórios da produção intelectual dos programas, em que os docentes apresentam para avaliação da Capes. Baseado nesses relatórios, foi feita a separação das produções pertencentes a cada programa. Esse método foi realizado somente para as duas docentes vinculadas a mais de um programa.

$\mathrm{Na}$ análise das redes de coautorias dos docentes somente as produções no nível de artigos de periódicos foram analisadas. Para melhor definição dos 
coautores, foram colhidos e agrupados dados sobre as instituições a que pertencem, as linhas de pesquisa, o vínculo existente nas instituições de ensino, a profissão, a formação e o estado. No que tange aos coautores estrangeiros, eram identificados a instituição, a profissão e a formação. Dessa forma, para cada docente foi pesquisado os seus coautores, esses dados foram tabulados no Microsoft Excel, agrupados, contabilizados e categorizados em interno e externo. Ressalta-se que parte dessas informações foram colhidas na descrição dos coautores em cada publicação.

Contudo, relata-se que houve obstáculos, pois, a maioria das publicações não forneciam as descrições que vinculassem a ocupação dos coautores, por isso, foi verificado nos currículos Lattes o vínculo durante o ano de publicação do artigo. Convém destacar que todas as informações referidas foram colhidas no período de 26 de dezembro de 2018 a 05 de janeiro de 2019, porém quatro artigos não foram localizados para identificação dos coautores, durante esse período.

Por conseguinte, foram categorizadas tais informações em internos e externos para melhor definição dos laços e das características que formam as redes. Os coautores internos foram categorizados em docentes pertencentes ao mesmo programa de pós-graduação, alunos de graduação, alunos da pósgraduação, bibliotecários e outros colaboradores da mesma instituição. Para os externos, as classificações ficaram em torno dos discentes e docentes pertencentes a outros programas de pós-graduação, discente de graduação e docentes de outras instituições, bibliotecários e outros colaboradores. Todos os colaboradores foram vinculados ao estado, país, instituição e formação. O objetivo foi estruturar e identificar os diversos tipos de relações e vínculos entre os docentes, programas, instituições e demais indivíduos que formam as redes de coautorias. Além de poder visualizar o alcance e dimensão geográfica das colaborações.

Logo após, foram utilizados os softwares UNICET e Netdraw, para geração dos grafos das redes de coautorias, no formato de sociograma. Os nós são os atores da rede e os laços existentes que unem os nós foram determinados pelas coautorias e a espessura dos laços, as frequências das colaborações, que 
são denominadas na rede de linhas ou arestas. Com o intuito de identificar o potencial das redes, foi calculado e tabelado com auxílio dos mencionados softwares, a densidade, a centralidade, a intermediação e a proximidade das redes.

Ressalta-se que adicionalmente, foi utilizado o software Wordle para representar a frequência das palavras referentes às formações das graduações dos coautores dos docentes, em formato de nuvem de palavras, que evidenciam as formações de acordo com a recorrência do texto analisado, ou seja, quanto mais a palavra for recorrente, maior é a palavra em relação às demais dentro do espectro da nuvem. Destarte, tem o intuito de identificar as áreas do conhecimento que contribuem para as produções, com uso dos dados das formações dos coautores, bem como contribuir para uma melhor visualização e compreensão da interdisciplinaridade da área de Biblioteconomia e Ciência da Informação da região Nordeste.

\section{CONSIDERAÇÕES FINAIS}

Ao ponderar que a pesquisa teve como cerne o estudo da produção dos docentes das pós-graduações da área de Biblioteconomia e $\mathrm{Cl}$, buscou-se, inicialmente, apresentar os fundamentos históricos que marcaram o surgimento, percurso e desenvolvimento, a fim de melhor entender as várias influências, as relações interdisciplinares, aplicabilidade e cientificidade que as formaram nas características que hoje são postas. Todo esse retrospecto se fez importante por clarificar o progresso da área, perceber a grandeza e a responsabilidade que têm nos seus estudos, técnicas e práticas interdisciplinares no uso da informação que contribuem para a sociedade, principalmente por vir evoluindo, consideravelmente nesta década, com os cursos de pós-graduação no país na região Nordeste.

Diante disso, com vistas ao fortalecimento e ampliação de novos programas para a região Nordeste, procurou compreender o sistema de comunicação científica e refletir sobre a importância do desenvolvimento de indicadores científicos, destacando o estudo bibliométrico e análise de redes sociais. Para tanto, infere o inegável papel da ciência na sociedade, no 
desenvolvimento econômico e no social, que por meio de indicadores dos estudos métricos da informação, viabilizam o avanço da ciência, permitindo a partir dos resultados um autoconhecimento e ponderações, além de visualizar a performance, traçar e acompanhar as atividades científicas, de modo a contribuir com as produções e evoluir ainda mais as áreas do conhecimento.

Nesta perspectiva, a bibliometria vem contribuir significativamente no ambiente científico, favorecendo os processos de produção, gestão, disseminação e recuperação da informação, bem como, aos quesitos administrativos, no planejamento e nas tomadas de decisões das atividades de pesquisa científica. Em conjunto com a análise de redes sociais, complementam na perspectiva social, um estudo mais aprofundado e detalhado sobre estrutura e a dinâmica das comunidades científicas, tal como os padrões sociais nas relações e interações na construção do conhecimento coletivo. Por conseguinte, consistem em importantes métodos que auxiliam na compreensão científica e social dos pesquisadores, além de contribuir na produtividade, na expansão e na formação de novas redes de colaboração.

Desta feita, revisitando os principais resultados da análise bibliométrica, foi possível constatar no processo evolutivo das produções, que há um esforço de crescimento no transcorrer dos cinco anos entre os programas, associado às avaliações quadrienais da Capes, mas também, uma heterogeneidade no ritmo de produção, com ascensões e declínios expressivos. Nesta senda, a compreensão do desenvolvimento científico da área e o acompanhamento são importantes para a gestão do conhecimento, no planejamento e na produtividade dos docentes. Outro ponto em destaque é a necessidade de aumentar a média de publicações por ano dos docentes, pois não atingem o recomendável pela Capes para a maioria dos programas. Adicionalmente, averiguou-se outra característica pelo padrão por encontros nacionais, bem como por um baixo índice em participação de eventos e periódicos internacionais, o que revela demandas a serem ampliadas para uma qualificação nas produções, uma melhor visibilidade e representatividade dos programas e de seus docentes.

Em relação aos periódicos científicos, foi demonstrado que os docentes têm optado pelas revistas de menor periodicidade, as trimestrais, assim como, 
por práticas endógenas, com uso massivo dos periódicos pertencentes aos próprios programas. No que tange à qualidade da produção intelectual dos programas, foram verificados os qualis dos periódicos publicados, que identificou preferências pelos estratos B1 e B5, o que pode significar uma ascensão e busca por maturidade nas pesquisas, além da existência de pequenos núcleos de periódicos mais produtivos em cada programa por meio da aplicação da lei de Bradford. De fato, com os dados colhidos e analisados na pesquisa, verificou-se outra característica nas produções, que os docentes são colaborativos, correspondendo a duas autorias presentes em todas tipologias estudadas na maioria dos programas, seguido de três autorias. $\mathrm{Na}$ análise de rede de coautoria, foi possível realizar um estudo elucidativo e aprofundado dos papeis e das deficiências nas relações colaborativas dos programas contemplados nas produções de artigos de periódicos.

Ressalta-se que outra intenção da pesquisa foi identificar o diálogo de interdisciplinaridade dos docentes dos programas de Biblioteconomia e $\mathrm{Cl}$ com outras áreas do conhecimento, tendo como base a quantificação das formações dos coautores, em que forneceu dados sobre as áreas mais próximas que influenciam e contribuem na construção da ciência. Com isso, esses resultados podem representar uma formação identitária cognitiva da área na região Nordeste, tendo em vista que se constatou uma proporção expressiva de colaboradores de distintas áreas, principalmente as mais próximas e correlatas nas produções analisadas, que refletem diferentes práticas de interdisciplinaridades, que beneficiam, principalmente, a Biblioteconomia, contribuindo e favorecendo as práticas de ensino, profissionais e sociais do bibliotecário.

\section{REFERÊNCIAS}

ARAÚJO, Carlos Alberto Ávila. Correntes teóricas da Biblioteconomia. Revista Brasileira de Biblioteconomia e Documentação. São Paulo, v. 9, n.1, p. 4158, jan./dez. 2013. Disponível em: https://rbbd.febab.org.br/rbbd/article/view/247. Acesso em: 20 fev. 2019. 
ARAÚJO, Carlos Alberto Ávila. Bibliometria: evolução história e questões atuais. Em Questão, Porto Alegre, v. 12, n. 1, p. 11-32, jan./jun. 2006.

Disponível em:

http://www.brapci.ufpr.br/documento.php?dd0=0000006356\&dd1=15c36.

Acesso em: 28 ago. 2016.

BRADFORD, Samuel Clement. Documentação. Rio de Janeiro: Fundo de Cultura, 1961.

COORDENAÇÃO DE APERFEIÇOAMENTO DE PESSOAL DE NÍVEL SUPERIOR. Diretoria de avaliação. Relatório da Avaliação Quadrienal 2017: Comunicação e Informação. Brasília, DF, 2017. Disponível em: http://capes.gov.br/images/stories/download/avaliacao/relatorios-finaisquadrienal-2017/20122017-Comunicacao-quadrienal.pdf. Acesso em 14 dez. 2018.

CRESWELL, John. Projetos de pesquisa: métodos qualitativo, quantitativo e misto. 2. ed. Porto Alegre: Artmed, 2007.

DIAS, Eduardo Wense. Biblioteconomia e ciência da informação: natureza e relações. Perspect. cienc. inf., Belo Horizonte, v. 5, n. especial, p. 67-80, jan./jun. 2000.

FIGUEIREDO, Nice. Tópicos modernos em Bibliometria. Brasília, DF: Associação dos Bibliotecários do Distrito Federal, 1977.

GALINDO, Marcos; AZEVEDO NETTO, Carlos Xavier de. Distribuição dos recursos de formação em Pós-graduação: o caso da Ciência da Informação no Nordeste do Brasil. In: ENCONTRO NACIONAL DE PESQUISA EM CIÊNCIA DA INFORMAÇÃO, 9., 2008, São Paulo. Anais [...]. São Paulo: USP, 2008. p. 1-12. Disponível em:

http://enancib.ibict.br/index.php/enancib/ixenancib/paper/viewFile/3089/2215 Acesso em: 25 jul. 2019.

GODOI, Christiane Kleinübing; BANDEIRA-DE-MELLO, Rodrigo; SILVA, Anielson Barbosa. (Org.). Pesquisa qualitativa em estudos organizacionais: paradigmas, estratégias e métodos. São Paulo: Saraiva, 2006.

KOBASHI, Nair Yumiko; SANTOS, Raimundo Nonato Macedo dos. Institucionalização da pesquisa científica no Brasil: cartografia temática e de redes sociais por meio de técnicas bibliométricas. Transinformação, Campinas, v. 18, n. 1, p. 27-36, jan./abr. 2006. Disponível em: http://www.scielo.br/scielo.php?pid=S010337862006000100003\&script=sci_abstract\&tlng=pt. Acesso em: 25 jul. 2019.

LE COADIC, Yves François. A ciência da informação. 2. ed. Brasília, DF: Briquet de Lemos, 2004. 
MELO, Natasha de Faria Neves. Análise da correlação entre produção científica, conhecimento inovador e impacto tecnológico nas Universidades Federais com investimento na infraestrutura da pesquisa. 2015. 122 f. Dissertação (Mestrado em Gestão Pública) - Universidade Federal de Pernambuco, Recife, 2015. Disponível em:

https://repositorio.ufpe.br/bitstream/123456789/16119/1/MPANE-NATASHA\%20Disserta\%c3\%a7\%c3\%a3o\%20-2015.pdf. Acesso em: 25 jul. 2019.

MIRANDA, Májory Karoline Fernandes de Oliveira. 0 custodialismo e a teoria da intencionalidade. Recife: Liber, 2012.

MUELLER, Suzana Machado Pinheiro. Avaliação do estado da arte da formação em Biblioteconomia e Ciência da Informação. Ci. Inf., Brasília, DF, v. 17, n. 1, p. 71-81, jan./jun., 1988. Disponível em: http://revista.ibict.br/ciinf/article/view/301/301 Acesso em: 25 jul. 2019.

ORTEGA, Cristina Dotta. Relações históricas entre biblioteconomia, documentação e ciência da informação. DataGramaZero, Rio de Janeiro, v. 5, n. 3, p. 1-16, out. 2004. Disponível em:

http://www.brapci.inf.br/index.php/article/download/7649 Acesso em: 25 jul. 2019.

OTLET, Paul. O livro e a medida: bibliometria. In: OTLET, Paul. Bibliometria: teoria e prática. São Paulo: Cultrix, 1986. p. 19-34.

RODRIGUES, Mara Eliane Fonseca; DUMONT, Ligia Maria Moreira. A Lógica da Organização e Distribuição do Conhecimento na Universidade: implicações no processo de ensino-aprendizagem, em especial, nas áreas de Biblioteconomia e Ciência da Informação. DataGramaZero, v. 5, n. 2, abr. 2004. Disponível em:

http://www.brapci.inf.br/index.php/article/view/0000001292/8f8679c571f5ab531 7622602abdd3ee6 Acesso em: 2 fev. 2019.

\section{RUSSO, Mariza. Fundamentos de Biblioteconomia e Ciência da} Informação. Rio de Janeiro: E-papers Serviços Editoriais, 2010.

SIDONE, Otávio José Guerci; HADDAD, Eduardo Amaral; MENA-CHALCO, Jesús Pascual. A ciência nas regiões brasileiras: evolução da produção e das redes de colaboração científica. TransInformação, Campinas, v. 28, n. 1, p. 15-31, jan./abr., 2016. Disponível em: http://www.scielo.br/pdf/tinf/v28n1/01033786-tinf-28-01-00015.pdf Acesso em: 22 fev. 2019.

SILVA, Antônio Braz de Oliveira e; MATHEUS, Renato Fabiano; PARREIRAS, Fernando Silva; PARREIRAS, Tatiane Aparecida Silva. Estudo da rede de coautoria e da interdisciplinaridade na produção científica com base nos métodos de análise de redes sociais: avaliação do caso do Programa de pós-graduação em Ciência da Informação - PPGCI/UFMG. Encontros Bibli, Florianópolis, n. especial, p. 179-194, 2006. Disponível em: 
https://periodicos.ufsc.br/index.php/eb/article/view/1518-

2924.2006v11nesp1p179/422 Acesso em: 15 fev. 2019.

SILVA, Jonathas Luiz Carvalho. Uma análise sobre a identidade da

Biblioteconomia: perspectivas históricas e objeto de estudo. Olinda: Edições

Baluarte, 2010.

SIQUEIRA, Jéssica Câmara. Biblioteconomia, documentação e ciência da informação: história, sociedade, tecnologia e pós modernidade. Perspectivas em Ciência da Informação, Belo Horizonte, v.15, n.3, p.52-66, set./dez 2010. Disponível em: http://www.scielo.br/pdf/pci/v15n3/04.pdf Acesso em: 20 fev. 2019.

SOUZA, Francisco das Chagas de. Os paradigmas da biblioteconomia e suas implicações no ensino desta ciência. Encontros Bibli: Florianópolis, v. 1, n. 2, 1996. Disponível em: https://periodicos.ufsc.br/index.php/eb/article/view/5/8 Acesso em: 25 jul. 2019.

TRIVIÑOS, Augusto Nibaldo Silva. Introdução à pesquisa em ciências sociais: a pesquisa qualitativa em educação. São Paulo: Atlas, 2011. Disponível em: https://periodicos.ufsc.br/index.php/eb/article/view/5/8. Acesso em: 22 abr. 2019.

VANZ, Samile Andréa de Souza. A bibliometria no Brasil: análise temática das publicações do periódico Ciência da Informação (1972-2002). In: ENCONTRO NACIONAL DE PESQUISA EM CIÊNCIA DA INFORMAÇÃO. 5., 2003, Belo Horizonte MG, Anais [...]. Belo Horizonte: ANCIB, 2003. p. 1-20. Disponível em: http://enancib.ibict.br/index.php/enancib/venancib/paper/view/1961 Acesso em: 15 fev. 2019.

\section{PRODUCTION AND SCIENTIFIC COLLABORATION OF POST-GRADUATE TEACHER IN BIBLIOTECONOMY AND INFORMATION SCIENCE IN THE NORTHEAST REGION: ANALYSIS FROM 2013 TO 2017}

\section{SUMMARY}

Introduction: For considering science in an accumulative perspective of productions and social in co-authoring relations. Objective: To analyze the indicators of scientific production and collaboration of teachers from the seven stricto sensu graduate programs in the Northeast region in Library and Information Science, from 2013 to 2017. Methodology: using bibliometrics and social network analysis as methods co-authored. Results: Regarding the scientific journals, it was demonstrated that the teachers have opted for the smaller journals, the quarterly ones, as well as for endogenous practices, with massive use of the journals belonging to the programs themselves. Conclusions: seeks to collaborate with the understanding, recognizing the characteristics and evolution of the area, identifying the specificities and patterns, with the purpose of promoting discussions, contributions and reflections on the productions of the area. 
Descriptors: Scientific production. Bibliometrics. Analysis of co-authoring networks.

\title{
PRODUCCIÓN Y COLABORACIÓN CIENTÍFICA DEL PROFESOR DE POSGRADO EN BIBLIOTECONOMÍA E CIENCIA DE LA INFORMACIÓN EN LA REGIÓN DEL NORESTE: ANÁLISIS DE 2013 A 2017
}

\begin{abstract}
RESUMEN
Introducción: Para considerar la ciencia en una perspectiva acumulativa de producciones y sociales en las relaciones de co-autoría. Objetivo: Analizar los indicadores de producción científica y colaboración de docentes de los siete programas de postgrado de stricto sensu en la región noreste en bibliotecología y ciencias de la información, de 2013 a 2017. Metodología: uso de bibliometría y análisis de redes sociales como métodos de co-autoría. Resultados: En cuanto a las revistas científicas, se demostró que los docentes optaron por revistas más pequeñas, trimestrales y prácticas endógenas, con un uso masivo de las revistas que pertenecen a los propios programas. Conclusiones: busca colaborar con la comprensión, reconociendo las características y evolución del área, identificando las especificidades y patrones, con el propósito de promover discusiones, aportes y reflexiones sobre las producciones del área.
\end{abstract}

Descriptores: Producción científica. Bibliometría. Análisis de las redes de co-autoría.

Recebido em: 25.07.2019

Aceito em: 09.09.2019 